\title{
A Study on PHERB Powertrain Modeling and Analysis
}

\author{
J. S. Norbakyah, A. R. Salisa
}

School of Ocean Engineering, Universiti Malaysia Terengganu, Malaysia

\begin{tabular}{l} 
Article Info \\
\hline Article history: \\
Received Jan 9, 2018 \\
Revised May 2, 2018 \\
Accepted May 10, 2018 \\
\hline
\end{tabular}

Keyword:

ADVISOR

Fuel economy

PHERB

Powertrain

\begin{abstract}
A study on plug-in hybrid electric recreational boat (PHERB) powertrain with a special energy management strategy modeling and analysis was presented in this paper. Firstly, the boat components are sized to meet the expected power and energy requirements through a power flow analysis. Then, the model is tested numerically in the MATLAB/SIMULINK environment using the existing driving cycle. The accuracy of the model is verified by a comparison of the component between the simulation results from PHERB and advanced vehicle simulator (ADVISOR) software. The simulation results of component, fuel economy and emission of PHERB and hybrid electric vehicle models in ADVISOR are compared.
\end{abstract}

Copyright $(0) 2018$ Institute of Advanced Engineering and Science. All rights reserved.

Corresponding Author:

A. R. Salisa,

Department of Electrical and Computer Engineering,

School of Ocean Engineering,

Universiti Malaysia Terengganu,

21030 Kuala Terengganu, Terengganu, Malaysia.

E-mail: salisa@umt.edu.my

\section{INTRODUCTION}

The world today is dealing with issues of oil reduction and harmful emissions are causing a primary transition of technology improvements from conventional internal combustion engine (ICE) powered automobiles to greater electricity efficient automobile powertrains. Plug-in hybrid electric vehicle (PHEV) are a promising alternative to fuel-best automobiles and provide the potential to substantially reduce fuel use in transportation. Marine transportation also need innovation in powertrain [1], [2]. To reduce the fuel consumption and emissions, Plug-in hybrid electric recreational boat (PHERB) was introduced [3], [4]. PHERB has only one electric machine (EM) to function as either an electric generator or motor in different time intervals specified by a special developed energy management strategy (EMS) that control the power flow according to desired operating mode [5], [6]. Figure 1 shows a block diagram of the proposed PHERB configuration, consists of an energy storage system (ESS), a power control unit (PCU), EM and an ICE [7], [8]. A proposed EMS is applied to the PHERB model to ensure the model achieve the target driving performance without sacrificing the optimum operating condition.

Based on Ghorbani et al., 2007, nowadays many researcher focus on understanding the dynamics of the hybrid vehicles by developing the simulators [9], [10]. The results can be used to optimize the design of hybrid vehicles by testing configurations and EMS before prototype construction begins. Power flow management, optimization of the fuel economy and reducing the emissions using intelligent control systems are part of the current research [11]-[14]. Practical and experimental verification of the vehicle simulators is an important part of ongoing researches [15]. Several computer programs have since been developed to describe the operation of hybrid electric powertrains [16], including advanced vehicle simulator (ADVISOR). 


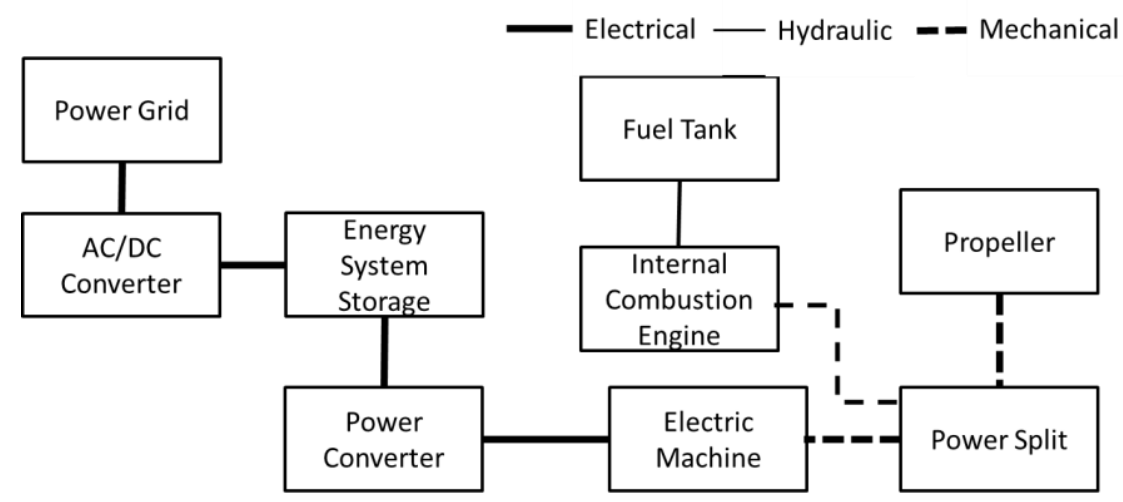

Figure 1. Block diagram of the PHERB powertrain [3]-[6]

\section{RESEARCH METHOD}

In this study, the method are divided in three phase. There is software used, PHERB modeling and EMS development. The software used are ADVISOR and MATLAB/SIMULINK. ADVISOR are used to model verification and MATLAB/SIMULINK used to development PHERB model.

\subsection{ADVISOR}

ADVISOR is a software based on MATLAB/SIMULINK, originally developed by the U. S. Department of Energy (DOE) and the National Renewable Energy Laboratory (NREL), to simulate and analyze light and heavy vehicles, including hybrid and fuel cell vehicles [17]. ADVISOR allows the user to perform analysis of the performance, emissions and fuel economy for conventional, electric and hybrid vehicles [18]. ADVISOR utilizes a backward looking vehicle simulation architecture, in which the required and desired vehicle speeds are used as the inputs to determine the required drivetrain torque, speed and power. The ADVISOR model vehicle contains two separate EMs which are used as the motor and generator, respectively, and no ultracapacitor (UC) in the ESS. The proposed PHERB, has only electric machine which functions as either a motor or generator at a time, specified by the special EMS, and an UC bank for fast charging and discharging during the regenerative braking and fast acceleration. To simulate the proposed PHERB, a model are derived in MATLBAB/SIMULINK environment. This model is verified by comparing the simulation results of the ADVISOR PHEV and PHERB powertrains.

\subsection{PHERB modeling}

The development of marine vehicle model begins with the calculations of boat energy and power requirements for typical driving conditions based on the parameters and target specifications of the boat based on PHERB specification, parameter and requirement that shown in Table 1 [3]-[6]. The size and capacity of each boat component are then determined through a power flow analysis accordingly to meet the requirements was listed in Table 2 .

Table 1. PHERB Parameters, Specifications And Performance Requirements

\begin{tabular}{ll}
\hline & Parameter and Specifications \\
Configuration & Series-Parallel \\
Length overall, L & $12.4 \mathrm{~m}$ \\
Length at waterline, LWT & $11.0 \mathrm{~m}$ \\
Breath, B & $1.8 \mathrm{~m}$ \\
Draught, T & $0.64 \mathrm{~m}$ \\
Length between perpendicular, LPP & $10.67 \mathrm{~m}$ \\
Density of water, $\rho$ & $1000 \mathrm{kgm}^{-3}$ \\
Total propulsive efficiencies, $\eta \mathrm{T}$ & 0.9 \\
& Performance Requirement \\
Maximum speed & Over $30 \mathrm{~km} / \mathrm{h}$ \\
EV range & $10 \mathrm{~km}$ \\
\hline
\end{tabular}


Table 2. Main Component Specification of PHERB

\begin{tabular}{ll}
\hline \multicolumn{1}{c}{ Component } & \multicolumn{1}{c}{ Specifications } \\
\hline ICE & $20 \mathrm{~kW} \mathrm{@} \mathrm{3000} \mathrm{rpm}$ \\
EM & $30 \mathrm{~kW} \mathrm{AC} \mathrm{induction} \mathrm{motor}$ \\
Battery & $\mathrm{Li}, 5 \mathrm{kWh}, 6 \mathrm{Ah}$ \\
\hline
\end{tabular}

Combining of all components obtain a mathematical model of the boat. The boat performance for a given EMS and driving cycle is simulated in the MATLAB/SIMULINK environment. Figure 2 illustrates the overall structure of the PHERB model in MATLAB/SIMULINK.

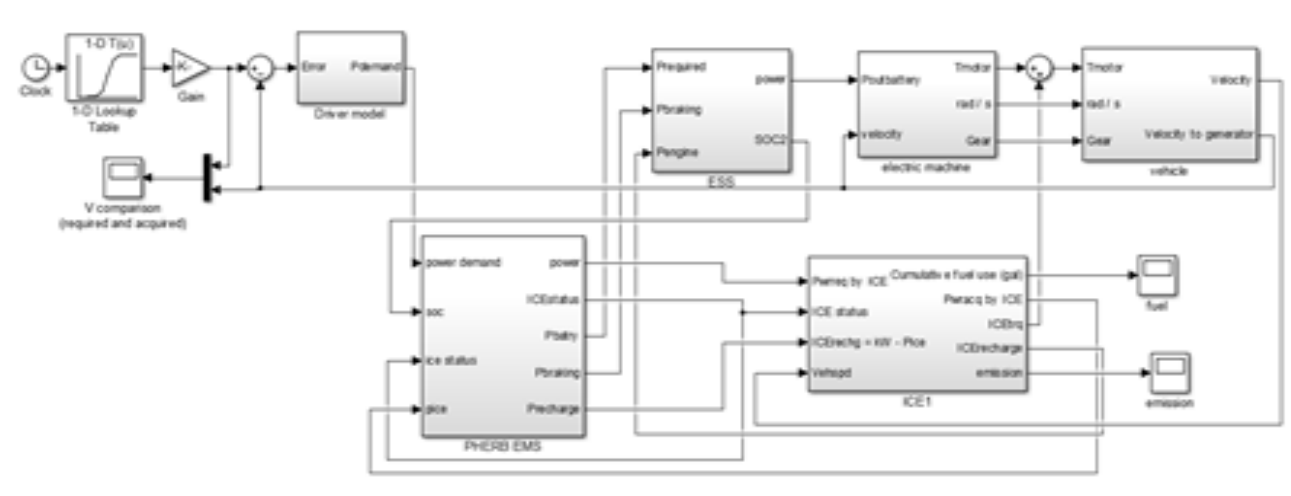

Figure 2. Overall structure of the PHERB model in MATLAB/SIMULINK

\subsection{Energy management strategy (EMS)}

The EMS is responsible for deciding in which mode that the boat is operating. Figure 3 shows various operation modes of the proposed EMS to control the distribution of power amongst the components, which are mechanical braking, regenerative braking, motor only, engine recharge, engine and motor assist and engine only mode according to the vehicle power demand in acceleration and deceleration and the ESS state of charge (SOC) level.

\begin{tabular}{|c|c|c|c|}
\hline & - Reverse mode & Forwarc & node \\
\hline High & $\begin{array}{l}\text { Mechanical } \\
\text { reverse mode }\end{array}$ & EM only mode & \\
\hline $\begin{array}{r}\text { SOC } \\
\text { Medium }\end{array}$ & Regenerative & $\begin{array}{l}\text { EM or ICE recharge } \\
\text { mode }\end{array}$ & combined mode \\
\hline SOC & reverse mode & ICE recharge mode & ICE mode \\
\hline soc & Low & Medium & High \\
\hline
\end{tabular}

Figure 3. Operation modes of EMS

\section{RESULT AND ANALYSIS}

In this section, model verification were analyze and discussed. For model verification, there is fourth model which is boat model, EM model, ESS model and propeller model. Besides that, fuel economy and emission were studied.

\subsection{Model verification simulation}

For a comparative study, the PHERB model is modified to incorporate the PHEV model in ADVISOR and energy management scheme. Three type of driving cycle used which are urban type is Manhattan driving cycle, suburb type is West Virginia suburban (WVUSUB) driving cycle, and highway 
type is the highway fuel economy driving schedule (HWFET) driving cycle. This illustrated driving cycle history time shown in Figure 4.

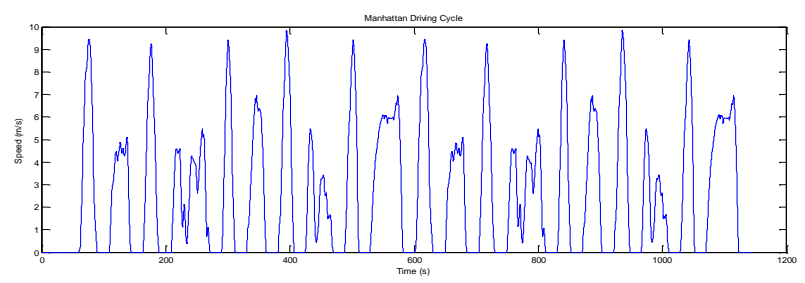

Manhattan driving cycle

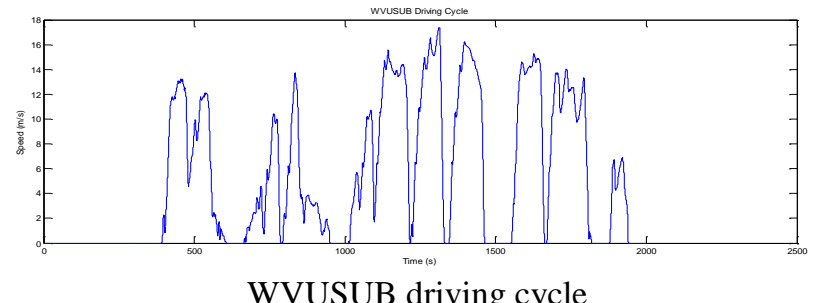

WVUSUB driving cycle

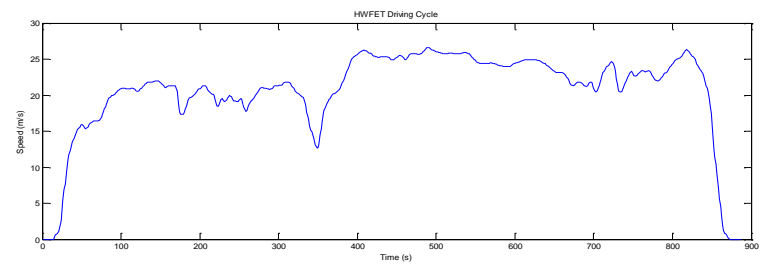

HWFET driving cycle

Figure 4. Time history for different driving cycle

The model verification simulation between ADVISOR and PHERB model are divided in four subsystem such as boat, ESS, EM and propeller model. In this model, the speeds and forces of PHERB are compared. The speeds and forces for the Manhattan, WVUSUB, and HWFET drive cycle are presented in Figure 5, Figure 6 and Figure 7. There is a close match between the PHEV model and PHERB model.

Figure 5, Figure 6 and Figure 7 show the simulated results of ESS current and ESS voltage for Manhattan, WVUSUB and HWFET drive cycles. The peak currents are due to the high power demand to achieve fast boat accelerations during the respective periods. The negative values on the graph represent the regenerative braking events during the hard braking periods in the cycle. In the ESS voltage graph, the voltage increases during recharging from regenerative braking and decreases during high current discharge when the power demand from EM is at peak. The PHERB model results for the Manhattan, WVUSUB and HWFET drive cycle exhibits values lower for the ESS current than that of ADVISOR model. For ESS voltage of PHERB shown higher value than ADVISOR model. Su/ch phenomenon is due to the power consumption of the boat under different EMS, and therefore can be accepted with a reasonable explanation. ESS SOC and ESS power are illustrated in Figure 5, Figure 6 and Figure 7 for Manhattan, WVUSUB and HWFET driving cycle. For ESS power, the overall trends of the energy consumption and generation of the two models match reasonably well. However, there is some differences between the ESS SOC results of the PHERB and ADVISOR model. This is because the PHERB model has a better EMS and can capture more regenerative braking energy.

The EM speed and torque of the PHERB and ADVISOR model for the Manhattan, WVUSUB, and HWFET driving cycle are included in Figure 5, Figure 6 and Figure 7. As shown in the simulation results, when the boat accelerates, the required motor/generator torque increases quickly, and when the vehicle reaches the relatively stable velocity level, a much smaller torque is required to overcome the resistance and drag to the boat. The speed and torque results simulation from two model are match and similarity. The average power demand from the motor/generator is in range 8-10 kW at Manhattan, WVUSUB and HWFET the velocity level and the peak power demand is $22-24 \mathrm{~kW}$ during the acceleration. From the results shown in Figure 5, Figure 6 and Figure 7, the EM power breaking for PHERB is higher than ADVISOR. The breaking power from EM can be used to recharge the ESS. The power results from the two model match reasonably well. 


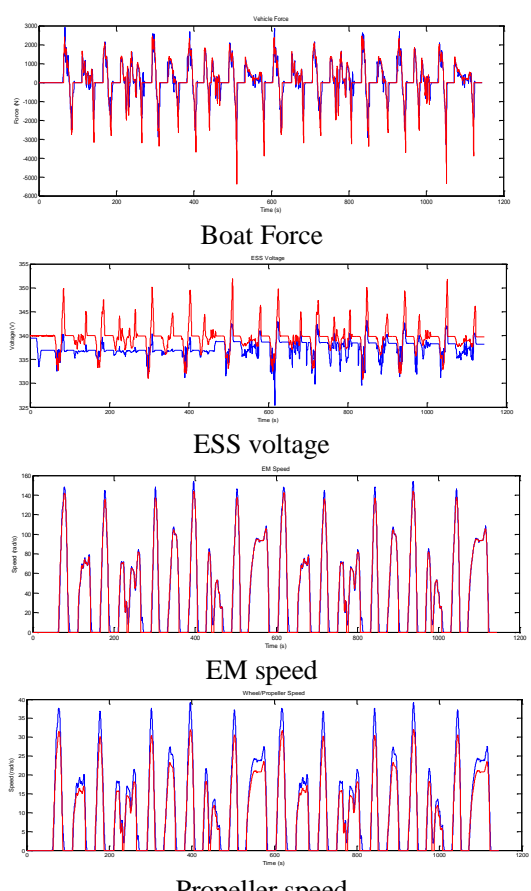

Propeller speed
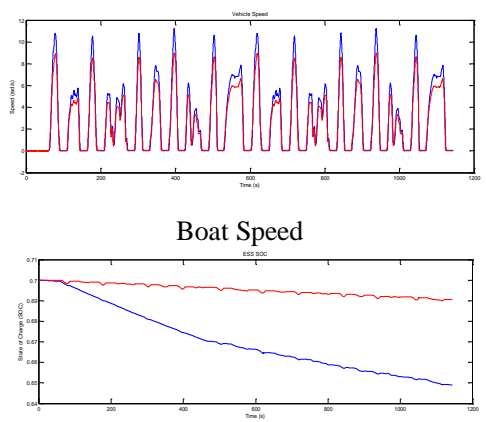

ESS SOC

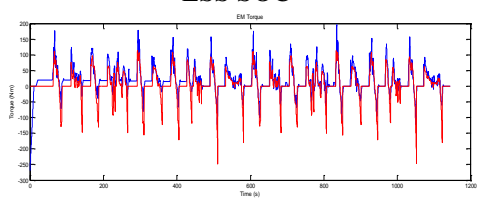

EM torque

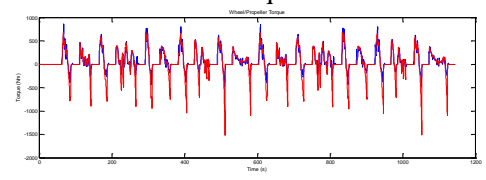

Propeller torque
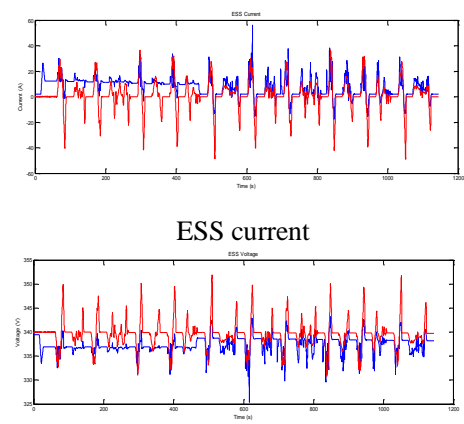

ESS power

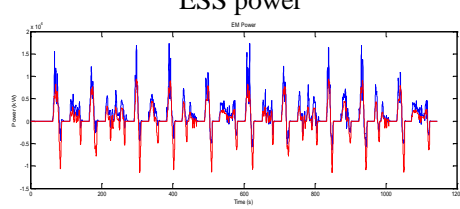

EM power

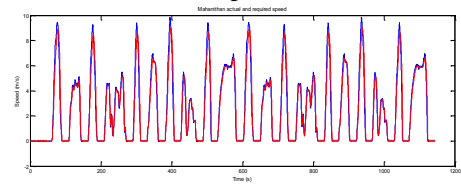

Acquired and required speed

Figure 5. Manhattan driving cycle (Blue: ADVISOR, Red: PHERB)
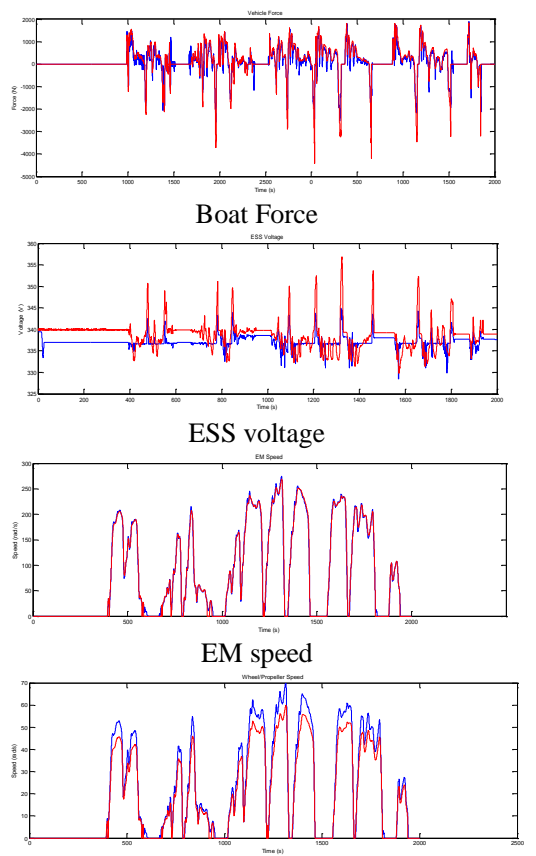

Propeller speed

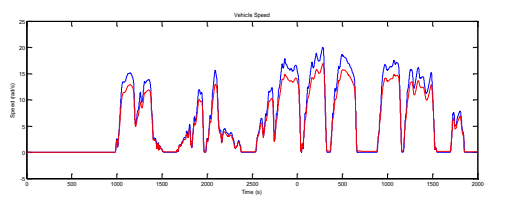

Boat Speed

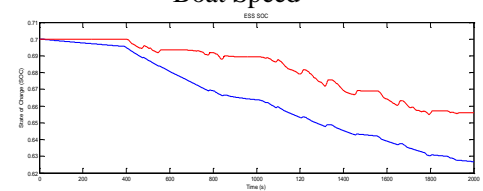

ESS SOC
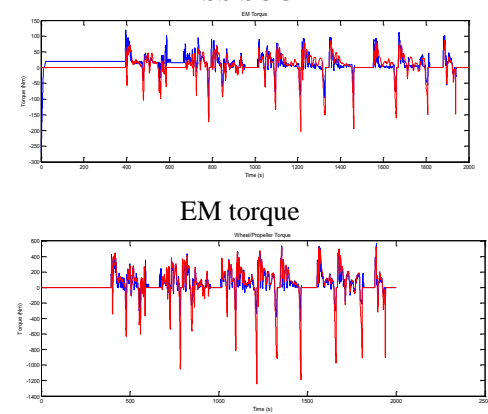

Propeller torque

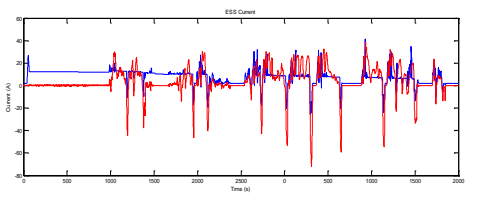

ESS current

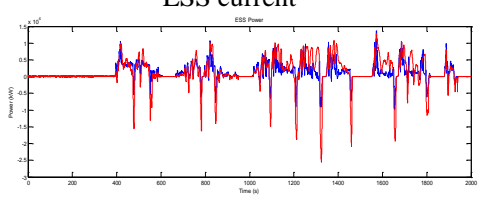

ESS power
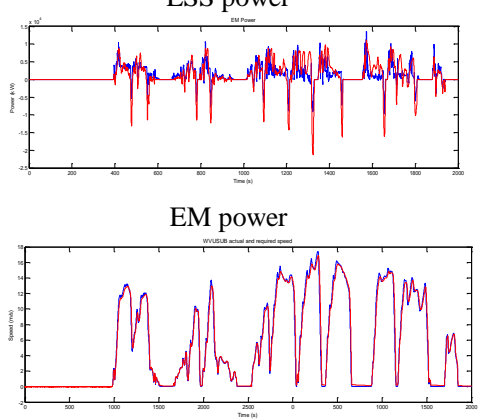

Acquired and required speed

Figure 6. WVUSUB driving cycle (Blue: ADVISOR, Red: PHERB)

Figure 5, Figure 6 and Figure 7 represent the propeller speed and torque requirement for the Manhattan, WVUSUB, and HWFET driving cycle simulated by two model. The result for propeller torque display the maximum torque in Manhattan driving cycle at $700 \mathrm{Nm}$, WVUSUB driving cycle at $600 \mathrm{Nm}$, and HWFET driving cycle at $800 \mathrm{Nm}$, occurs when the vehicle is accelerating from stop to the speed. The required torque then reduces since the driving cycle only consists of mild accelerations and decelerations. The overall results and trends match very closely. 
The acquired and required speeds of the Manhattan, WVUSUB, and HWFET drive cycle is plotted in Figure 5, Figure 6 and Figure 7. It can be seen that acquired and required speeds agree reasonably well. The PHERB followed the required drive cycle speed very well for the standard drive cycle used.
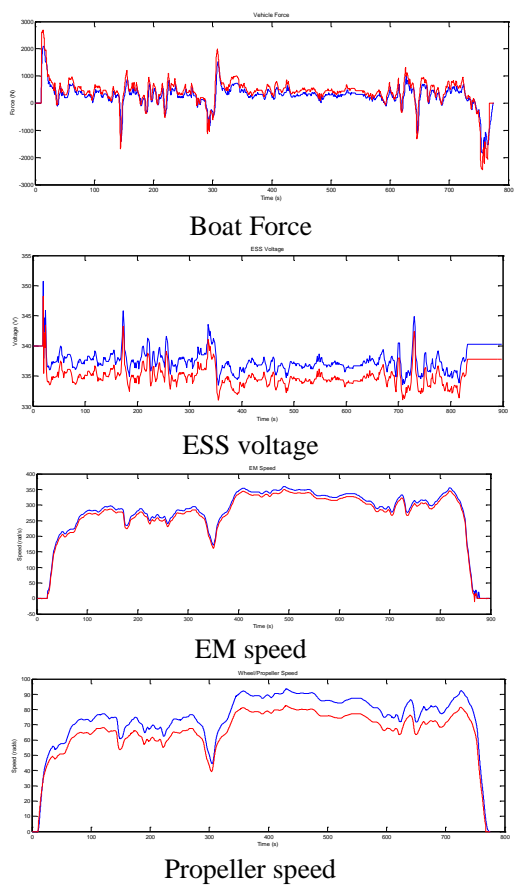
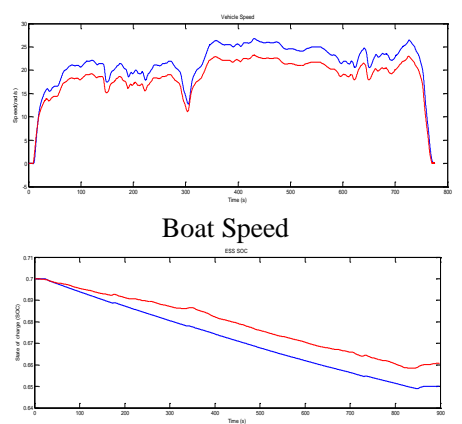

ESS SOC

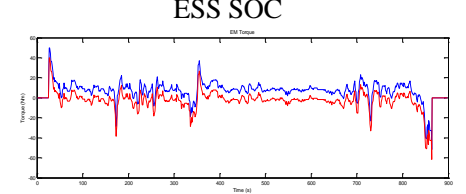

EM torque

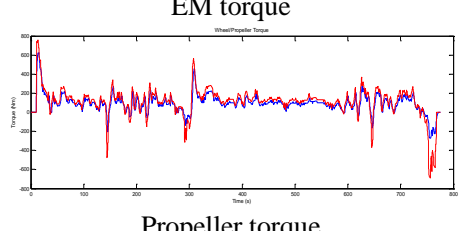

Propeller torque

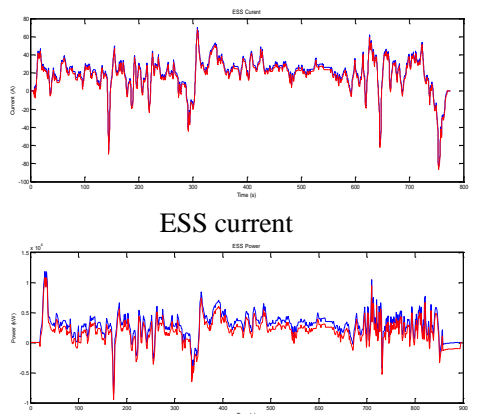

ESS power
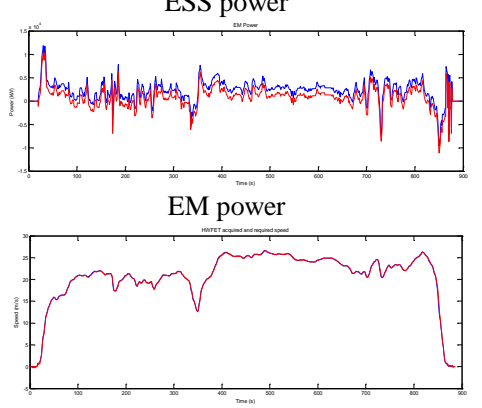

Acquired and required speed

Figure 5. HWFET driving cycle (Blue: ADVISOR, Red: PHERB)

\subsection{Fuel economy and emission analysis}

This study compares the fuel economy (FE) and emissions of PHERB model and ADVISOR model configuration shown in Table 3 such as hydro-carbon (HC), carbon-monoxide (CO), and nitrogen-dioxide (NOx) for the HWFET, Manhattan and WVUSUB drive cycles. The FE can be determined using Equation (1) [19], [20] where D is distance in miles and Vfuel is volume of fuel in consumed in gallons.

FE mpg $=\mathrm{D} /$ Vfuel

The PHERB model is simulated using a specially developed EMS. SOC are important part in EMS although not related to the component sizing but it give the impact in FE and emission. The FE and emissions for different drive cycles are given in Table 3.

Table 3. The FE and emission

\begin{tabular}{ccccccccc}
\hline & \multicolumn{3}{c}{ PHERB } & \multicolumn{2}{c}{ ADVISOR } \\
Driving Cycle & $\begin{array}{c}\text { Fuel } \\
\text { Economy } \\
(\mathrm{mpg})\end{array}$ & $\mathrm{HC}$ & $\mathrm{CO}$ & $\mathrm{NOx}$ & $\begin{array}{c}\text { Emission }(\mathrm{g} / \mathrm{m}) \\
\text { Economy } \\
(\mathrm{mpg})\end{array}$ & HC & CO & NOx \\
\hline Manhattan & 58.2 & 1.172 & 0.599 & 0.000 & 39.5 & 1.787 & 2.058 & 0.318 \\
WVUSUB & 88.9 & 0.507 & 0.260 & 0.000 & 64.2 & 0.558 & 0.697 & 0.173 \\
HWFET & 97.3 & 0.224 & 0.203 & 0.047 & 87.6 & 0.394 & 0.602 & 0.183 \\
\hline
\end{tabular}

Table 3 shows the improvement in the FE and emissions were achieved by the PHERB model. Based on the analysis results, the following observations can be made. The FE of the PHERB is about $32 \%$ improve than ADVISOR model in Manhattan driving cycle, $28 \%$ in WVUSUB driving cycle and $10 \%$ in HWFET driving cycle. While for emission PHERB model shows the result of three type emission such as $\mathrm{HC}, \mathrm{CO}$, and NOx decreased compared to the ADVISOR model. This happen because PHERB ESS model have battery and UC bank where UC played an important role for the improvement of FE and emissions hence the ADVISOR model has only the battery in the ESS. 


\section{CONCLUSION}

The results of the PHERB model boat subsystems in terms of ESS current, ESS voltage, ESS power, ESS SOC, motor/generator speed and torque, boat speed and force and propeller speed and torque are within reasonable and predictable range of actual typical behavior of PHEV. The components of the boat subsystems are suitably sized as the vehicle is accomplished of achieving performance. In previous discussion, it can be concluded that results of the PHERB model are correct.

\section{ACKNOWLEDGEMENTS}

The authors would like to be obliged to Universiti Malaysia Terengganu (UMT) for UMT Scholarship, Ministry of Education Malaysia for providing financial assistance under FRGS (59353) grant and School of Ocean Engineering, UMT for all their technical and research support for this work to be successfully complete.

\section{REFERENCES}

[1] J. S. Norbakyah, W. H. Atiq, A. R. Salisa, 2015, "Component Sizing in PHERB Powertrain Using PK Driving cycle”, Journal of Scientific Research and Development, vol. 2, no. 12, pp. 39-42.

[2] K. Dominik, H. Chris and R. Aymeric, 2008, "Impact of Component Size on Plug-In Hybrid Vehicle Energy Consumption Using Global Optimization”, The World Electric Vehicle Journal, vol. 2, no. 2.

[3] J. S. Norbakyah, W. H. Atiq, A. R. Salisa, 2015, Powertrain Main Components Sizing Of PHERB Using KL River Driving Cycle", ARPN Journal of Engineering and Applied Sciences, vol. 10, no. 18, pp. 8507-8510.

[4] M. Z. Daud, K. Z. Kin, J. S. Norbakyah, A. R. Salisa, 2015, "An Optimal Electric Machine Control System Design Used In Plug-In Hybrid Electric Boat", ARPN Journal of Engineering and Applied Sciences, vol. 10, no. 22, pp. 10703-10708.

[5] J. S. Norbakyah, W. H. Atiq, A. R. Salisa, 2015, "Impact Component Sizing on PHERB Powertrain using Tasik Kenyir Driving Cycle", Australian Journal of Basic and Applied Sciences, vol. 9, no. 25, pp. 56-59.

[6] J. S. Norbakyah, W. H. Atiq, A. R. Salisa, 2015, "Components Sizing for PHERB Powertrain using ST River Driving Cycle", 2015 IEEE International Conference on Computer, Communication, and Control Technology (I4CT 2015) Kuching, Sarawak, Malaysia.

[7] B. K. Powell, K. E. Bailey and S. R. Cikanek, 1998, "Dynamic Modeling and Control of Hybrid Electric Vehicle Powertrain Systems", IEEE Control Systems, pp. 272-1708.

[8] L. B. Karen, E. Mehrdad and K. Preyas, 1999, "A Matlab-Based Modeling and Simulation Package for Electric and Hybrid Electric Vehicle Design”, IEEE Transactions on Vehicular Technology, vol. 48, no. 6, pp. 1770-1778.

[9] S. R. Cikanek, K. E. Bailey, B. K. Powell, 1997, "Parallel Hybrid Electric Vehicle Dynamic Model and Powertrain Control", Proceedings of the American Control Conference, Albuquerque, New Mexico.

[10] R. Ghorbani, E. Bibeau, P. Zanetel, A. Karlis, 2007, "Modeling and Simulation of a Series Parallel Hybrid Electric Vehicle Using REVS", 2007 American Control Conference, New York, NY, pp. 4413-4418.

[11] L. Ippoliot, V. Loia, P. Siano, 2003, "Extended Fuzzy C-Means and Genetic Algorithms to Optimize Power Flow Management in Hybrid Electric Vehicles", Fuzzy Optimization and Decision Making, vol. 2, pp. 359-374.

[12] P. Bowles, H. Peng, X. Zhang, 2000, "Energy Management in a Parallel Hybrid Electric Vehicle with a Continuously Variable Transmission", American Control Conference Chicago, Illinois, June 2000.

[13] Jong-Seob Won, R. Langari, M. Ehsan, 2005, “An Energy Management and Charge Sustaining Strategy for a Parallel Hybrid Vehicle with CVT", IEEE Transactions on control system technology, vol. 13, no. 2, March 2005.

[14] D. Hermance, S. Sasaki, 1998, "Hybrid electric vehicles take the streets", IEEE Spectrum, pp. 4852.

[15] C. Bourne, P. Faithfull, C. Quigley, 1996, "Implementing Control of a Parallel Hybrid Vehicle", International Journal of Vehicle Design, vol. 17, no. 5-6. pp. 649-662.

[16] K. L. Bulter, M. Ehsani, P. Kamath, 1999, "A Matlab-based modeling and simulation package for electric and hybrid electric vehicle design”, IEEE Transaction of Vehicular Technology, vol. 48, no. 6.

[17] B. K. Wipke, 1999, "ADVISOR 2.1: A User-friendly Advanced Powertrain Simulation using a Combined Backward/forward Approach”, IEEE Transactions on Vehicular Technology, vol. 48, pp. 1751-1761.

[18] S. Abdul Rahman, N. Zhang, J. Zhu, 2008, "Modeling and Simulation of an Energy Management System for Plug-in Hybrid", Electric Vehicles Australasian Universities Power Engineering Conference.

[19] J. Gonder, A. Simpson, 2007, "Measuring and Reporting Fuel Economy of Plug-In Hybrid", Electric Vehicles WEVA Journal, vol. 1, pp 1-8.

[20] S. Abdul Rahman, N. Zhang, J. Zhu, 2011, "A Comparison on Fuel Economy and Emissions for Conventional Hybrid Electric Vehicles and the UTS Plug-in Hybrid Electric Vehicle IEEE Transactions on Vehicular Technology", vol. 60, pp 44-54.

\section{BIOGRAPHIES OF AUTHORS}




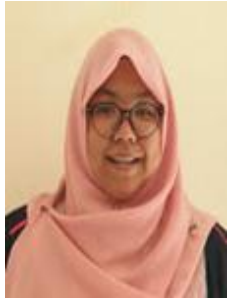

J. S. Norbakyah received the Bachelor of Applied Science (Physics Electronic and Instrumentation) and Master of Science from Universiti Malaysia Terengganu, Terengganu, in 2009 and 2014 respectively and currently pursuit his Doctor of Philosophy degree in Energy Technology in Universiti Malaysia Terengganu. Her main research interest is Electric Vehicle, Hybrid Electric Vehicle, Plug in Hybrid Vehicle, Modelling and simulation and renewable energy

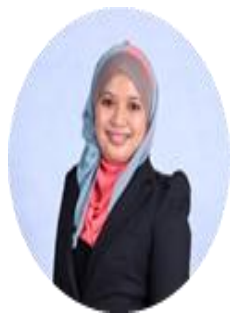

A. R. Salisa received the B.E. and M.E. in Electrical \& Electronics Engineering from University of Technology Petronas, Perak, Malaysia in 2004 and 2006, respectively while Ph.D. in Optimal Energy Management Strategy for the University of Technology Sydney Plug-In Hybrid Electric Vehicles from University of Technology Sydney (UTS), Australia. She is currently working as a senior lecturer at University Malaysia Terengganu, Malaysia. Her research interests are in Hybrid Electric Vehicles, innovation powertrain, simulation and modeling, energy management strategy, driving cycles, fuel economy, emissions and optimization. 